\title{
Biomedical Research: On-Going Challenges
}

\author{
Kingsley Akarowhe* \\ Department of Educational Foundations, Guidance and Counselling, Faculty of Education, University of Uyo, Uyo, Nigeria
}

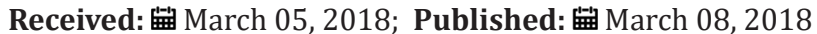

*Corresponding author: Kingsley Akarowhe, Department of Educational Foundations, Guidance and Counselling, Faculty of Education, University of Uyo, Uyo, Akwa Ibom State, Nigeria, Telephone no: +234-08137640978; Email: kingsmith1172@gmail.com

\begin{abstract}
Biomedical research is aimed at proffering solutions to problems facing biomedical profession, so as to enhance productivity of biomedical practitioners. Biomedical profession in recent time has not achieved major successes for which it is directed to achieve. This is often due to a number a bedevilling on-going challenge. It is due to this fact that the research take a proactive step in investigating these challenges which are inaccurate/inadequate statistical data; lack of sufficient awareness; non-responsiveness of respondents; and lack of finance.
\end{abstract}

Keywords: Biomedical Research; on-going Challenges

\section{Meaning of Biomedical Research}

Biomedical research or experimental medicine encompasses a wide array of research from basic research also called bench science or bench research [1,2] Biomedical research involves the explanation of more fundament scientific principles, to clinical research, which is distinguished by the involvement of patients, within this spectrum is applied research, or translation research conducted to aid and support the development of knowledge in the field of medicine, and pre-clinical research, for example involving animals [1]. Biomedical research is a scientific investigation into biological aspect and medicine aspect of human endeavour with a view of providing solutions to the problems facing it. Similarly, it can be seen as an enquire into the issues affecting an organism; and medicine induced issues in a given society, with the aim of providing insight on way such issues can be solved. Biomedical research is geared toward increasing productivity of biomedical practitioners in the short-run and on the long-run the health sector of a given country.

On-going Challenges in Biomedical Research and Biomedical Practices

\section{Inaccurate/Inadequate Statistical Data}

Accurate/adequate statistical data are essential for research to be effectively carried out for its purpose to be achieved. Biomedical research depends on relevant data from patients, medical centers, hospital, medical practitioners and other relevant source. Hence, when the statistical data are adequate and accurate it will aid biomedical research in providing solution to the problem of interest which will in the long-run assist medical practitioners' efficiency in their job. In developing countries there are often cases of inadequate/ inaccurate statistical data. This is due to the fact that practitioners often do not record, sort, and preserve necessary information that would assist biomedical researchers in their quest of providing solution to challenges facing biomedical practices. To supplement this [3] submitted that in the less developed countries, dental restoration process has an administrative lags of inadequate statistical records about patient by most dentist. Additionally, most biomedical practitioners do not record patients' keen information while in some other cases there is lack of appropriate storage of such information when provided. This tends to hinder biomedical researchers from obtaining valid data for onward process for the purpose of improving the condition of biomedical practices.

\section{Lack of Sufficient Awareness}

Awareness is a means of enlighten the public about a given issue of concern which seems to affect them [4]. Awareness is a product for accomplishing the goals of a suitable research and increase productivity of practitioners. In medical research, awareness is a keen variable of updating pragmatic approaches with novel approaches in the process of carrying out a specific investigation. Biomedical research is faced with lack of sufficient awareness among practitioners. This is usually shown in outdated approaches in which some of the carry out their research in the health/medical sector. This is often as a result of lack of access 
to sufficient information and proven information made available by biomedical researchers to them. Overtime this has lead to monotonous practices by most practitioners in providing solution to a given medical problem, which might not yield the needed result as anticipated.

\section{Non-Responsiveness of Respondents}

Research is an enquiry into a specific problem with the aim of providing solution to it. For this aim to be effectively achieved, respondents (patients) must be willing to respond to biomedical researchers positively by responding to issues raised by the researchers. In other words, there must be a high level of commitment from the patients, in terms of responding to biomedical researchers directives during the process of the investigation. Due to non-responsiveness by the respondents much information have been left untapped by most biomedical researcher. This also seems to pave way for insufficient data to be used in the process of providing solution to problem of concern.

\section{Lack of Finance}

For research to be effectively carried out there must be sufficient financial backing. This is due to the fact that research is highly financial intensive. Biomedical research unlike any other type of human research entails/comprise of exploring into cost effective equipment by biomedical researchers, unlike other human research were less financial implication is attached to it. In other words, biomedical research highly dependent on financial capacity of the researcher. Shortage or lack of finance in the process will result in futility of the entire process or insufficient result for the problem for which enquire is made on. This will leads to nonaccomplishment of the purpose which the study was initially set-up to provide solution to.

\section{Conclusions and Recommendations}

To provide a lasting solution to the multifaceted on-going challenges facing biomedical research, statistical data should be properly accounted for by biomedical practitioners and provided as at when needed by biomedical researchers; sufficient finance should be made available for biomedical researchers who are making investigating into issues/problems facing biomedical practices; awareness campaign should be provided for biomedical researchers and practitioners; and lastly, respondents (patients) attitude toward biomedical researchers should be change in other for the researchers to achieve the aim of their investigation.

\section{References}

1. Association of American Medical Colleges (2016) Basic Science. Ammc org Retrieved, USA.

2. Wikipedia (2017).

3. Akarowhe K (2018) Challenges Faced by Dental Patients Undergoing Dental Restoration in the Less Developed Countries. Open Access Journal of Surgery 8(3): 1-3.

4. Akarowhe K (2018) A Case Study of Pharmacovigilance in Nigeria: Meaning; Component; Challenges and Solutions. Journal of Pharmacovigilance and Pharmaco Therapeutics.

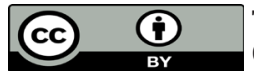

This work is licensed under Creative Commons Attribution 4.0 License

To Submit Your Article Click Here: Submit Article

DOI: 10.32474/OAJBEB.2018.01.000118

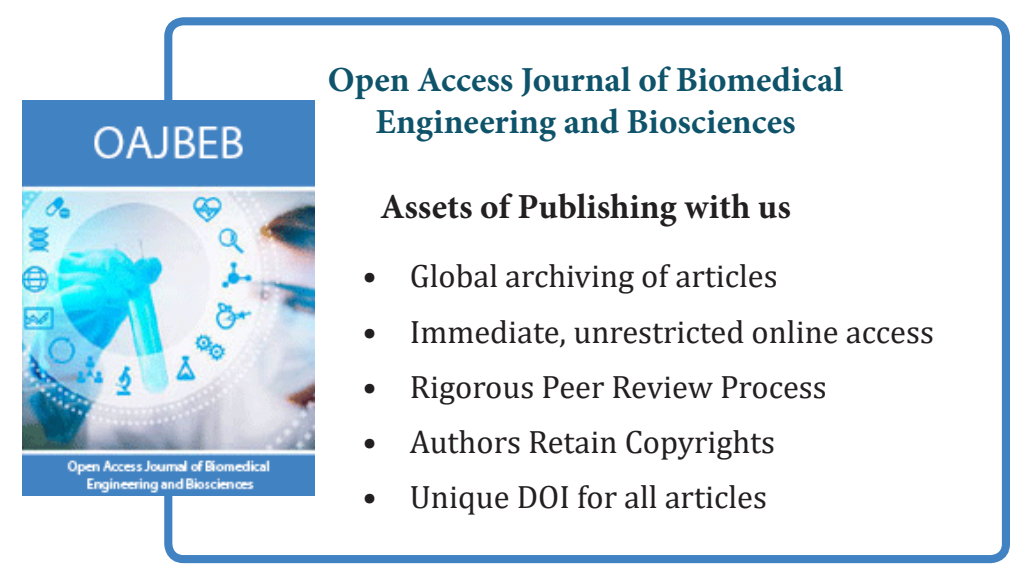

